\title{
CANDO A CRISE CHE EXIME. O SECTOR DA DISTRIBUCIÓN E O COMERCIO AO POR MENOR ESPAÑOL: PEQUENAS Vs GRANDES EMPRESAS
}

Remedios RAMÓN DANGLA ${ }^{\dagger}$

Universidade de Alicante. Departamento de Economía Financeira e Contabilidade.

\begin{abstract}
Resumo Neste traballo analizamos como o sector do comercio ao por menor evolucionou nun contexto de crise. Establecemos as hipóteses sobre o seu comportamento por mor da especialización na venda de bens de primeira necesidade, así como das dificultades para acceder ao crédito. Obtivemos unha mostra de empresas da base SABI e clasificámolas por tamaños. Estudamos a evolución de ratios de eficiencia, operatividade, rendibilidade ou solvencia e procuramos os cambios estatisticamente significativos nas ratios dependendo do tamaño empresarial, o que permitiunos afirmar que só as pequenas empresas perderon rendibilidade e tiveron que reorganizar a súa estrutura financeira.

Palabras chave: Crise financeira; Comercio ao por menor, tamaño empresarial, autonomía financeira, rendibilidade.

Title: When the crisis exempts you: the spanish retailer sector: small vs big companies

Abstract In this paper, we analyze how the Spanish retailer trade sector has developed in a context of crisis. Then, we stablished the hypothesis about the particular behavior of the sector because of specialization in the sale of basic goods and as well as, the problems to get credit. We found an example of companies from the database SABI, then we sorted the sample by size, we studied the evolution of rates from efficiency, operability, profitability or financial solvency and we searched the statistically significant changes on the rates depending of company size. We could conclude that, only for the small companies, the actual crisis has generated a little loss of profitability but especially, the crisis has generated a big change into the financial structure.

Key words: Financial crisis; retail trade; size business; financial sustainability; profitability.
\end{abstract}

\section{INTRODUCIÓN}

A distribución comercial española sofreu importantes cambios nas últimas décadas. Os novos hábitos de consumo da sociedade, a integración vertical e o desenvolvemento das denominadas marcas brancas fixeron que o panorama do comercio minorista de España cambiara. A posición dominante dalgunhas cadeas de distribución no comercio ao por menor, tanto sobre os provedores como sobre os consumidores, xeraron preocupación nas autoridades da competencia española e europea (García, J.A. e Delgado, J., 2012) e propiciaron un comportamento excepcional perante a actual crise económica.

Nun sistema económico capitalista, a un período no que existen forzas ascendentes que provocan acumulación de ganancias e investimento, séguelle outro con forzas no senso contrario que desemboca en depresión económica e social (Keynes J., 1936). É dicir, as crises económicas xéstanse lentamente durante os períodos de crecemento e especulación e xurden mediante un choque violento de depresión e unha reestruturación económica (Galbraith, 1991). Neste senso, a actual Gran Crise provocada pola economía Norteamericana en agosto de 2007 co estoupido das hipotecas subprime e a súa rápida expansión ao resto do mundo a través do sector financeiro, xestouse por unha regulación financeira permisiva e uns baixos tipos de interese que alimentaron unha burbulla inmobiliaria, tanto en EEUU como noutros países europeos, como por exemplo, España. A economía estaba desaxustada: máis de dous terzos do PIB estaban relacionados coa vivenda e cos seus créditos, o cal non era sostible (Stiglitz, 2010). A explosión da burbulla inmobiliaria arrastrou un sistema financeiro cheo de produtos complexos baseados no crédito inmobiliario. A expansión do crédito e o exceso de liquidez internacional dos anos de crecemento económico provocaron un nivel de endebedamento privado máis aló do razoable e por tanto, calquera perturbación baseada nun aumento de tipos de interese, restricións de liquidez empresarial ou sinxelamente, nunha redución dos beneficios esperados por debaixo do custo dunha refinanciación ían provocar unha crise financeira, máis

\footnotetext{
remedios.ramon@ua.es http://web.ua.es/es/defc/remedios-ramon-dangla.html
} 
grande canto maior fora o grao de globalización económica e de sofisticación dos produtos financeiros (Minsky, 1976).

A confianza nos bancos para emprestar cartos entre eles desapareceu e os mercados mundiais financeiros derribáronse, o que provocou unha caída da demanda e un colapso da produción. Era imprescindible afrontar unha nova reestruturación económica no mundo e reorganizar os niveis de endebedamento empresarial (Stiglitz, 2010).

Os excesos inmobiliarios e o elevado volume de débeda do sector privado precipitaron a caída da economía española. Os activos de moitas empresas perderon valor e as súas taxas de beneficios non cubrían os pagamentos da débeda daí que os balances das entidades financeiras se deteriorasen, sobre todo, os das máis expostas ao sector inmobiliario. A redución de marxes financeiras e a desconfianza no sistema pecharon o acceso ao crédito e colapsouse a economía produtiva. A caída do PIB e do emprego puxeron de manifesto que España entrara en recesión no segundo trimestre de 2008 e permanecería así ata a actualidade porque, o leve crecemento iniciado no primeiro trimestre de 2010 foi interrompido pola crise da débeda soberana estendida por algúns países europeos (Ortega e Peñasola, 2012). A renda dispoñible nos fogares contraíuse traducíndose nunha redución do consumo a partir do terceiro trimestre de 2008 (Boletín Económico do ICE, 2011).

O obxectivo desta investigación é ver como afectou a crise económico-financeira ao sector da distribución comercial en España e, se a existencia de grandes cadeas de distribución, coas súas propias marcas e forte poder de negociación nos mercados, permitiulles evadir unha potente reestruturación dos seus estados contables. Para iso, o traballo foi estruturado en catro apartados ademais desta introdución. En primeiro lugar realízase unha revisión da literatura sobre as principais variables a estudar e que supoñen o punto de partida desta investigación. A continuación, desenvólvense as hipóteses do modelo e explícase a metodoloxía utilizada para acadar os obxectivos formulados. Seguidamente analízanse os resultados obtidos. E, por último, expóñense as conclusións do traballo, entre as que se inclúen a discusión dos resultados e as principais implicacións para a xestión empresarial, limitacións e futuras liñas de investigación.

\section{REVISIÓN DA LITERATURA}

Crise financeira, endebedamento empresarial e sector económico

É abundante a literatura económica sobre as causas e efectos das crises financeiras ao longo da historia (Minsky, 1976; Galbraith, 1991, por citar algúns), así como as revisións sobre a teoría clásica dominante que levou á actual crise (Stiglitz, 2010; Krugman, 2009), que coinciden en que a situación actual se parece á dos anos trinta do século pasado e que os desaxustes déronse pola predominancia das doutrinas que cren que "os mercados funcionan ben e se autorregulan", defendidas, entre outros, polos Premios Nobel de Economía Harry Markowitz e William Sharpe en 1990 ou Robert Merton e Myron Scholes en 1997.

Non hai dúbida de que a evolución das variables macroeconómicas condiciona a evolución das contas empresariais, de tal modo que existen innumerables estudos que amosan que o endebedamento empresarial está estreitamente relacionado coa evolución de variables macroeconómicas. Neste senso, podemos destacar a Jordà et al. (2011), que despois de analizar as recesións económicas de 1870 e 2008 en catorce países desenvolvidos, relaciona o endebedamento das empresas e a inestabilidade da economía, concluíndo que existe unha clara relación entre o apancamento financeiro, medido pola taxa de crecemento do crédito bancario en relación ao PIB en etapas de expansión, e a dureza que presentan as etapas de recesión posteriores.

No caso español, é necesario considerar as consecuencias que se derivaron do ingreso no euro e que coincide co patrón de comportamento descrito por Fernández (2010) cando indica que a política de baixos tipos de interese formulada polos bancos centrais, asolagou o mercado cun exceso de liquidez que estimulou ás familias, empresas e bancos a endebedarse en exceso sen considerar que, ao longo da historia, todas as crises financeiras 
viñeron precedidas de grandes crecementos do crédito. A diferenza nas preferencias polo endebedamento das empresas españolas con respecto aos seus veciños vén avalada pola tese de Rajan e Zingales (1995); Demirgüç-Kunt e Maksimovic, (1999); Booth et al., (2001); Hanousek e Shamshur (2011), que defenden o argumento de que os custos e os beneficios que as empresas teñen en conta nas súas decisións de estrutura de capital non só veñen determinados polas súas características específicas, senón tamén polas características do país.

Nos seus traballos de investigación, Schularick e Taylor (2012) establecen a comparación entre o volume total de activos bancarios e a cifra de empréstitos bancarios en circulación con algúns dos agregados monetarios habituais (M2 ou M3), afirmando que os cambios na oferta de crédito (empréstitos bancarios) son o mellor indicador que anuncia as crises financeiras, especialmente cando estes cambios se producen de maneira acelerada. Nembargantes, Rubio e Sogorb (2011) conclúen que as empresas españolas, en contradición coa evidencia empírica internacional e cos estudos precedentes de Miguel e Pindado (2001) e González e González (2008), móvense con maior rapidez cara ratios obxectivas de endebedamento nas fases de contracción do ciclo económico que nas expansivas.

Azofra et al. (2012) e González e Jareño (2014) sinalan con respecto ao tamaño empresarial e o sector de pertenenza que aparecen diferenzas significativas no comportamento financeiro. A grande empresa exhibe maiores niveles de apancamento, xa que a súa maior dimensión lle permite eludir problemas de selección adversa e información asimétrica asociada a maiores volumes de activo, pero a pequena dependerá máis do crédito bancario, o que lle dificultará máis a saída da crise.

3. HIPÓTESES FORMULADAS E METODOLOXÍA

O obxectivo do noso traballo é ver como afectou a crise económica ao sector da comercialización e distribución en España: CNAE 2009-Rev2 471: Comercio ao por menor en establecementos non especializados e en que medida. As táboas 1 e 2 resumen a evolución do sector no período 2008-2012.

Táboa 1: Evolución do PIB p.m. Gasto Medio por Fogar, Cifra Neta de Negocio das empresas do sector 471, Evolución dos Asalariados en España e no sector 471.

\begin{tabular}{cccccc}
\hline & PIB pm & Gasto Medio Fogar & $\begin{array}{c}\text { Cifra Neta } \\
\text { Negocio 471 }\end{array}$ & $\begin{array}{c}\text { Asalariados } \\
\mathbf{4 7 1}\end{array}$ & $\begin{array}{c}\text { Asalariados } \\
\text { España }\end{array}$ \\
\hline $\mathbf{2 0 0 8}$ & 100,00 & 100,00 & 100,00 & 100,00 & 100,00 \\
$\mathbf{2 0 0 9}$ & 96,67 & 95,20 & 98,06 & 98,60 & 94,00 \\
$\mathbf{2 0 1 0}$ & 96,84 & 92,82 & 97,86 & 97,03 & 92,00 \\
$\mathbf{2 0 1 1}$ & 96,32 & 91,86 & 99,72 & 97,48 & 90,55 \\
$\mathbf{2 0 1 2}$ & 94,53 & 88,75 & 99,36 & 93,93 & 85,38 \\
\hline
\end{tabular}

Números Índice baseados en 2008=100. Fonte: INE. Ministerio Emprego e elaboración propia

As hipóteses formuladas expóñense no Anexo e son as seguintes:

H1: O sector da distribución e comercialización ao por menor CNAE 471 sofreu con menor intensidade os efectos da crise.

H2.1: Malia que as empresas do sector da distribución ao por menor sentiron menos a crise, a dificultade para acceder ao crédito e o seu encarecemento orixinou un efecto de desapancamento e de recapitalización dos fondos propios.

H2.2: Non todas as empresas do sector van estar afectadas pola reestruturación financeira. As máis grandes, con maior capacidade de negociación con entidades de crédito e sobre todo, 
con acredores, apenas terán necesidade de recompoñer a súa débeda namentres as máis pequenas tratarán de substituír débeda allea por autofinanciación.

Táboa 2: Evolución do importe dos Empréstitos e Créditos a Empresas non Financeiras e do Pasivo non Corrente das empresas do sector 471.

Números Índices baseados $2008=100$

\begin{tabular}{lll}
\hline $\mathbf{2 0 0 8}$ & 100,00 & 100,00 \\
$\mathbf{2 0 0 9}$ & 93,39 & 96,87 \\
$\mathbf{2 0 1 0}$ & 71,57 & 95,50 \\
$\mathbf{2 0 1 1}$ & 56,77 & 92,13 \\
$\mathbf{2 0 1 2}$ & 52,18 & 89,57 \\
\hline
\end{tabular}

Fonte: INE. Elaboración propia

A caída do PIB, o aumento do desemprego e a diminución dos salarios entre 2008 e 2012 tivo que afectar directamente ás empresas que se adican ao comercio nacional aínda que a especialización en venda de bens cunha elasticidade e renda baixa quizabes amortiguou os efectos negativos da crise. Para o noso estudo, agrupamos por tamaños as empresas do sector CNAE 2009-Rev2 471 en España ofrecida pola base de datos SABI e a Central de Balance do Banco de España (BdE).

A poboación de partida foi de 14.832 empresas e sobre ela, aplicamos 3 filtros. No primeiro eliminamos todas as sociedades que non estiveran activas en todos os anos estudados (20082012) e que non presentaran a información financeira completa. A submostra obtida foi de 2.814 empresas.

Posteriormente, clasificamos estas empresas por tamaños segundo a Directiva Europea 2013/34/UE do Parlamento Europeo e do Consello do 26 de xuño de 2013, sobre os estados financeiros anuais, os estados financeiros consolidados e outros informes afíns de certos tipos de empresas, o que deu como resultado: 54 grandes empresas, 47 medianas; 925 pequenas e 1788 microempresas. Destes catro grupos, eliminamos o último por representar empresas moi pequenas, cun Total Activo (TA) inferior a $350.00 €$ e unha Cifra Neta de Negocio (CNN) inferior a $700.000 €$ pero sobre todo foron eliminados pola pouca calidade informativa.

O terceiro filtro que utilizamos foi excluír da nosa mostra ás empresas dependentes da súa matriz e que consolidan a súa información financeira con ela. Así, obtemos finalmente unha mostra de 1.103 empresas das que calculamos diversas ratios económico-financeiras.

Para a análise da información estatística elaboramos un panel de datos e contrastamos o valor medio obtido polas ratios obxecto de estudo mediante a análise da varianza univariante e multivariante. Rexeitamos as ratios que amosaban unha alta correlación entre elas e aquelas que non cumprían coa normalidade e a homoxeneidade das varianzas. Posteriormente, comprobamos se existiron cambios nas medias mostrais de cada unha das ratios seleccionadas dende el inicio da crise 2008 ata o ano 2012, mediante un contraste de hipótese bilateral e cun intervalo de confianza do $95 \%$. A través do estatístico $\mathrm{F}$ na proba Anova, contrastamos a hipótese nula de igualdade de medias para cada grupo de ratios no período obxecto de estudo. Posteriormente, aplicamos unha análise multivariante Post Hoc de Tuckey HDS (Honestlysignificant-difference) ou Manova comparada, dúas a dúas, os nosos grupos de variables para ver se, nos casos onde se rexeitou a hipótese nula de igualdade de medias, afecta a todos os pares de medias ou pola contra, só afecta a algún deles.

A definición de ratios utilizada inclúese no Anexo. 


\section{RESULTADOS E ANÁLISE}

\section{Análise da conta de Perdas e Ganancias: \\ Ratios operativas ou de rendibilidade (RO)}

A táboa 8 amosa o resumo dos estatísticos descritivos das variables empregadas para analizar a rendibilidade e operatividade das empresas despois de eliminar as ratios que non cumpren a homoxeneidade das varianzas.

Táboa 8 Estatísticos descritivos RO e análise da varianza: 2008, 2010, 2012

\begin{tabular}{|c|c|c|c|c|c|c|c|c|c|c|c|c|}
\hline & \multicolumn{3}{|c|}{$\begin{array}{c}\text { Pequenas } \\
\text { N:1011 }\end{array}$} & \multicolumn{3}{|c|}{$\begin{array}{c}\text { Medianas } \\
\quad \mathrm{N}: 47\end{array}$} & \multicolumn{3}{|c|}{$\begin{array}{c}\text { Grandes } \\
\text { N: } 45\end{array}$} & \multicolumn{3}{|c|}{$\begin{array}{c}\text { Total } \\
\text { N: } 1103\end{array}$} \\
\hline 2008 & Mediana & Media & DT & Mediana & Media & DT & Mediana & Media & DT & Mediana & Media & DT \\
\hline R01 & 0,123 & 0,142 & 0,09 & 0,114 & 0,119 & 0,08 & 0,117 & 0,112 & 0,05 & 0,121 & 0,140 & 0,09 \\
\hline R02 & 0,021 & 0,026 & 0,06 & 0,025 & 0,027 & 0,04 & 0,020 & 0,019 & 0,04 & 0,021 & 0,026 & 0,06 \\
\hline R03 & 1,975 & 2,357 & 1,49 & 2,395 & 2,576 & 1,27 & 1,993 & 2,230 & 0,93 & 1,990 & 2,361 & 1,46 \\
\hline R05 & 0,028 & 0,038 & 0,09 & 0,057 & 0,069 & 0,12 & 0,031 & 0,035 & 0,10 & 0,028 & 0,039 & 0,09 \\
\hline 2010 & Mediana & Media & DT & Mediana & Media & DT & Mediana & Media & DT & Mediana & Media & DT \\
\hline R01 & 0,131 & 0,151 & 0,09 & 0,105 & 0,111 & 0,08 & 0,113 & 0,114 & 0,04 & 0,128 & 0,148 & 0,09 \\
\hline RO2 & 0,016 & 0,024 & 0,07 & 0,020 & 0,033 & 0,04 & 0,023 & 0,014 & 0,04 & 0,017 & 0,024 & 0,07 \\
\hline R03 & 1,851 & 2,207 & 1,39 & 2,212 & 2,504 & 1,41 & 1,780 & 2,060 & 0,87 & 1,881 & 2,214 & 1,37 \\
\hline R05 & 0,019 & 0,031 & 0,09 & 0,040 & 0,074 & 0,10 & 0,033 & 0,024 & 0,10 & 0,021 & 0,032 & 0,09 \\
\hline 2012 & Mediana & Media & DT & Mediana & Media & DT & Mediana & Media & DT & Mediana & Media & DT \\
\hline R01 & 0,130 & 0,154 & 0,09 & 0,114 & 0,132 & 0,09 & 0,125 & 0,124 & 0,05 & 0,130 & 0,152 & 0,09 \\
\hline R02 & 0,012 & 0,012 & 0,06 & 0,020 & 0,027 & 0,04 & 0,020 & 0,002 & 0,08 & 0,013 & 0,012 & 0,06 \\
\hline R03 & 1,937 & 2,258 & 1,45 & 2,092 & 2,368 & 1,10 & 2,016 & 2,143 & 0,90 & 1,963 & 2,258 & 1,41 \\
\hline R05 & 0,012 & 0,013 & 0,09 & 0,029 & 0,053 & 0,10 & 0,020 & $-0,014$ & 0,20 & 0,013 & 0,014 & 0,10 \\
\hline
\end{tabular}

Fonte: Elaboración propia. DT = desviación típica.

Dos estatísticos descritivos das RO podemos intuír que se produciron cambios significativos nalgunhas das ratios. As caídas nos gastos pero sobre todo, nos resultados pode que causara retrocesos na operatividade destas empresas. Para comprobar se a media de cada RO difire ou non, de maneira significativa como consecuencia da crise, realizamos unha análise univariante da varianza Anova cun nivel de significación de 0,05. A táboa A1 do anexo e atendendo ao estatístico $\mathrm{F}$ e ao p-valor xurdido da análise Anova podemos ver que efectivamente, para o grupo de pequenas empresas do sector 471 producíronse cambios significativos nas medias do RO1; RO2 e RO5. Se consideramos o conxunto do sector, a hipótese nula de igualdade de medias pódese rexeitar nunha ratio operativa máis: RO3. O que se confirma coa análise Post Hoc Manova (Táboa M1 do anexo).

As distintas rendibilidades medidas polo grupo de ratios $\mathrm{RO}$ foron caíndo no sector como consecuencia do empeoramento da situación económica. A perda de operatividade produciuse fundamentalmente nas pequenas empresas pero, dado o seu elevado peso sobre o conxunto total, fai que tamén caian as rendibilidades do total do sector. Neste senso, vese que, tanto nas pequenas empresas como no conxunto, a Produtividade da Man de Obra, medida por (RO1), cae. Os gastos de persoal (GP) creceron porcentualmente por enriba da cifra neta de negocio (CNN), o que se podería deber ao custo dos despedimentos. 
En termos xerais, o emprego no sector caiu en torno a un $6 \%$ pero os gastos laborais creceron un $7,5 \%$ nas pequenas empresas e un $20 \%$ no conxunto. Esta diverxencia de valores e evolucións entre emprego e custos laborais, podería avalar a tese de que a financiación do despedimento e o redimensionamento empresarial minguaron a operatividade do sector. Nembargantes, parece razoable supoñer que, unha vez satisfeitas as indemnizacións, a xestión do cadro de persoal será máis eficiente e polo tanto mellorará a produtividade.

En canto á Marxe de Explotación RO2, (relación Resultados de Explotación REX e CNN) podemos apreciar que, tanto na pequena empresa como no conxunto do sector produciuse un empeoramento. A redución da marxe de explotación vén motivada por unha forte caída no resultado de explotación de máis dun $12 \%$ no conxunto do sector e dun $45 \%$ para o caso das pequenas empresas. O descenso nos resultados de explotación vén motivado por unha caída nas vendas pero sobre todo, por un incremento dos gastos de explotación como son os gastos de persoal, os fixos e outros gastos adicionais que limitou a rendibilidade das empresas.

A caída da ratio de Rotación de Activo (RO3) entre 2008 e 2010 no conxunto das empresas amosa que, en xeral, o sector dispoñía de activos que non estaban sendo utilizados para xerar negocio. Porén, a partir de 2010 comeza a recuperarse, o que podería ser sintomático dunha reactivación do negocio.

Con respecto á Rendibilidade sobre Activos (RO5) observamos, tanto nas pequenas empresas como no total, que a caída dos resultados se acentúa como consecuencia da redución dos resultados de explotación e da obtención duns resultados financeiros negativos que, malia que van dimunuíndo a consecuencia do desapancamento, non conseguen compensar o seu efecto negativo, o que se traduce nunha caída da rendibilidade empresarial.

Ratios Financeiras (RF)

A análise do resultado financeiro amósase mediante o resumo dos estatísticos descritivos das RF (Táboa 9).

Táboa 9 Estatísticos descritivos RF e análise da varianza: 2008, 2010, 2012

\begin{tabular}{|l|r|r|r|r|r|r|r|r|r|r|r|r|}
\hline & \multicolumn{2}{|c|}{ Pequenas. N:1011 } & \multicolumn{2}{|c|}{ Medianas. N: 47 } & \multicolumn{3}{|c|}{ Grandes. N: 45 } & \multicolumn{3}{c|}{ Total. N: 1103 } \\
\hline 2008 & Mediana & Media & DT & Mediana & Media & DT & Mediana & Media & DT & Mediana & Media & DT \\
\hline RF1 & 0,005 & 0,010 & 0,01 & 0,002 & 0,008 & 0,01 & 0,003 & 0,008 & 0,00 & 0,005 & 0,140 & 0,01 \\
\hline RF4 & $-0,164$ & $-0,139$ & 4,98 & $-0,025$ & $-0,053$ & 0,42 & 0,026 & $-0,577$ & 5,94 & $-0,147$ & $-0,153$ & 4,92 \\
\hline $\mathbf{2 0 1 0}$ & Mediana & Media & DT & Mediana & Media & DT & Mediana & Media & DT & Mediana & Media & DT \\
\hline RF1 & 0,003 & 0,007 & 0,01 & 0,002 & 0,004 & 0,00 & 0,002 & 0,008 & 0,01 & 0,003 & 0,007 & 0,01 \\
\hline RF4 & $-0,105$ & $-2,835$ & 82,97 & $-0,002$ & 0,053 & 0,57 & $-0,001$ & 0,030 & 0,63 & $-0,089$ & $-2,593$ & 79,4 \\
\hline 2012 & Mediana & Media & DT & Mediana & Media & DT & Mediana & Media & DT & Mediana & Media & DT \\
\hline RF1 & 0,004 & 0,008 & 0,01 & 0,004 & 0,005 & 0,00 & 0,003 & 0,008 & 0,01 & 0,004 & 0,008 & 0,01 \\
\hline RF4 & $-0,106$ & 0,119 & 9,37 & $-0,026$ & 0,079 & 1,40 & $-0,010$ & 0,288 & 2,37 & $-0,097$ & 0,124 & 8,97 \\
\hline
\end{tabular}

Fonte: Elaboración propia. DT = desviación típica.

A evolución das medias das ratios financeiras (RF) dános pistas que algúns deles puideron mellorar ao longo do período producindo cambios significativos nas medias dos mesmos. Para comprobar se a media de cada RF difire ou non, de maneira significativa como consecuencia da crise, realizamos unha análise univariante da varianza Anova cun nivel de significación de 0,05 e cuxos resultados se amosan na táboa A2 do anexo. Atendendo ao estatístico $\mathrm{F}$ e ao p-valor xurdido da análise Anova rexeitamos a hipótese nula de igualdade de medias para o RF1 e nos grupos de empresas pequenas, medianas e o total. Tamén rexeitamos a hipótese de igualdade de medias no RF3 tanto para pequenas empresas como para o conxunto total. O que se confirma coa análise Post Hoc Manova (Táboa M2 do anexo). 
Análise da liquidez a través das ratios correntes (RC)

Táboa 10 Estatísticos descritivos RC e análise da varianza: 2008, 2010, 2012

\begin{tabular}{|c|c|c|c|c|c|c|c|c|c|c|c|c|}
\hline \multirow[b]{2}{*}{2008} & \multicolumn{3}{|c|}{ Pequenas N:1011 } & \multicolumn{3}{|c|}{ Medianas. N: 47} & \multicolumn{3}{|c|}{ Grandes. N: 45} & \multicolumn{3}{|c|}{ Total. N: 1103} \\
\hline & $\begin{array}{l}\text { Media- } \\
\text { na }\end{array}$ & Media & $\begin{array}{l}\text { Dev } \\
\text { Tip }\end{array}$ & $\begin{array}{c}\text { Media- } \\
\text { na }\end{array}$ & Med. & $\begin{array}{l}\text { Dev } \\
\text { Tip }\end{array}$ & $\begin{array}{c}\text { Media- } \\
\text { na }\end{array}$ & Media & $\begin{array}{l}\text { Dev } \\
\text { Tip }\end{array}$ & $\begin{array}{c}\text { Media- } \\
\text { na }\end{array}$ & Media & $\begin{array}{l}\text { Dev. } \\
\text { Tip }\end{array}$ \\
\hline RC2 & 0,061 & 0,124 & 0,16 & 0,030 & 0,097 & 0,15 & 0,030 & 0,074 & 0,19 & 0,058 & 0,121 & 0,17 \\
\hline RC3 & 0,000 & 0,046 & 0,10 & 0,112 & 0,137 & 0,09 & 0,154 & 0,151 & 0,10 & 0,000 & 0,054 & 0,10 \\
\hline $\mathrm{RC4}$ & 0,060 & 0,083 & 0,31 & 0,026 & 0,040 & 0,13 & 0,065 & $-0,043$ & 0,12 & 0,052 & 0,076 & 0,30 \\
\hline RC5 & 1,263 & 1,866 & 2,80 & 1,116 & 1,577 & 1,64 & 0,743 & 0,840 & 0,40 & 1,235 & 1,812 & 2,71 \\
\hline RC6 & 0,755 & 1,123 & 1,66 & 0,677 & 1,068 & 1,41 & 0,394 & 0,492 & 0,38 & 0,727 & 1,095 & 1,63 \\
\hline RC7 & 0,166 & 0,421 & 0,95 & 0,085 & 0,330 & 0,91 & 0,049 & 0,163 & 0,26 & 0,153 & 0,406 & 0,03 \\
\hline 2010 & $\begin{array}{c}\text { Media } \\
\text { na }\end{array}$ & Media & $\begin{array}{l}\text { Dev } \\
\text { Tip }\end{array}$ & $\begin{array}{c}\text { Media } \\
\text { na }\end{array}$ & Med. & $\begin{array}{l}\text { Dev. } \\
\text { Tip }\end{array}$ & $\begin{array}{c}\text { Media } \\
\text { na }\end{array}$ & Media & DT & $\begin{array}{c}\text { Media } \\
\text { na }\end{array}$ & Media & $\begin{array}{l}\text { Dev. } \\
\text { Tip }\end{array}$ \\
\hline RC2 & 0,049 & 0122 & 0,16 & 0,030 & 0,103 & 0,15 & 0,032 & 0,075 & 0,17 & 0,047 & 0,119 & 0,16 \\
\hline RC3 & 0,000 & 0,049 & 0,11 & 0,101 & 0,122 & 0,08 & 0,149 & 0,148 & 0,10 & 0,000 & 0,056 & 0,11 \\
\hline $\mathrm{RC4}$ & 0,077 & 0,119 & 0,27 & 0,050 & 0,073 & 0,16 & $-0,078$ & $-0,040$ & 0,13 & 0,069 & 0,111 & 0,26 \\
\hline RC5 & 1,360 & $-0,883$ & 91,5 & 1,173 & 1,655 & 1,42 & 0,693 & 0,945 & 0,84 & 1,335 & 0,699 & 87,5 \\
\hline RC6 & 0,756 & $-1,508$ & 85,0 & 0,839 & 1,098 & 1,16 & 0,376 & 0,603 & 0,72 & 0,731 & 1,309 & 81,4 \\
\hline RC7 & 0,175 & $-0,767$ & 38,2 & 0,099 & 0,253 & 0,34 & 0,052 & 0,189 & 0,54 & 0,160 & 0,684 & 36,5 \\
\hline 2012 & $\begin{array}{c}\text { Media- } \\
\text { na }\end{array}$ & $\begin{array}{c}\text { Medi } \\
\mathbf{a}\end{array}$ & .Tip & $\begin{array}{c}\text { Media } \\
\text { na }\end{array}$ & Med. & $\begin{array}{l}\text { Dev. } \\
\text { Tip }\end{array}$ & $\begin{array}{c}\text { Media } \\
\text { na }\end{array}$ & Media & $\begin{array}{l}\text { Dev. } \\
\text { Tip }\end{array}$ & $\begin{array}{c}\text { Media } \\
\text { na }\end{array}$ & Media & $\begin{array}{l}\text { Dev. } \\
\text { Tip }\end{array}$ \\
\hline RC2 & 0,039 & $\begin{array}{c}0,11 \\
1\end{array}$ & 0,16 & 0,026 & 0,070 & 0,13 & 0,037 & $\begin{array}{c}0,07 \\
2\end{array}$ & 0,17 & 0,038 & 0,107 & 0,16 \\
\hline RC3 & 0,000 & $\begin{array}{c}0,04 \\
5\end{array}$ & 0,11 & 0,093 & 0,095 & 0,06 & 0,134 & $\begin{array}{c}0,13 \\
6\end{array}$ & 0,09 & 0,000 & 0,051 & 0,11 \\
\hline RC4 & 0,076 & $\begin{array}{c}0,12 \\
3\end{array}$ & 0,31 & 0,044 & 0,054 & 0,15 & $-0,070$ & $\begin{array}{l}0,05 \\
2\end{array}$ & 0,13 & 0,072 & 0,112 & 0,30 \\
\hline RC5 & 1,377 & $\begin{array}{c}2,18 \\
9\end{array}$ & 3,21 & 1,180 & 1,533 & 1,07 & 0,686 & $\begin{array}{c}0,93 \\
9\end{array}$ & 0,95 & 1,332 & 2,108 & 3,09 \\
\hline RC6 & 0,714 & $\begin{array}{c}1,27 \\
9\end{array}$ & 2,17 & 0,816 & 0,995 & 0,91 & 0,417 & $\begin{array}{c}0,61 \\
7\end{array}$ & 0,83 & 0,704 & 1,238 & 2,09 \\
\hline RC7 & 0,177 & $\begin{array}{c}0,48 \\
6\end{array}$ & 0,96 & 0,130 & 0,246 & 0,32 & 0,063 & $\begin{array}{c}0,22 \\
1\end{array}$ & 0,61 & 0,170 & 0,464 & 0,93 \\
\hline
\end{tabular}

Fonte: Elaboración propia

Ao estudar a evolución entre os gastos financeiros e a CNN descrita en RF1 advírtese que, tanto para a pequena empresa, como a mediana e o total, a relación era de equilibrio malia que amosaba unha peor posición que a do grupo de grandes empresas. O desapancamento financeiro nos grupos de pequenas e medianas empresas aliviaron as súas cargas financeiras sobre a cifra neta de negocio, así, os gastos financeiros foron caíndo e, en 2012, os valores do (RF1) igualáronse ao das grandes empresas, os que partían dunha mellor relación financeira e, polo tanto, non sofreron cambios significativos, non por ter un menor volume de débeda, senón por 
ter unha maior e mellor capacidade de financiación froito do seu gran tamaño.

As medias das ratios de circulante (RC) indican que pode que existiran cambios significativos en varios deles. Tanto os aumentos das ratios que miden os activos circulantes como a redución nas ratios que consideran os pasivos correntes, poderían revelar que a liquidez inmediata das empresas está mellorando. Para comprobar se a media de cada RC difire ou non, de maneira significativa como consecuencia da crise, realizamos unha análise univariante da varianza Anova cun nivel de significación de 0,05 e cuxos resultados se amosan na táboa A3 do Anexof. Atendendo ao estatístico $\mathrm{F}$ e ao p-valor xurdido da análise Anova podemos ver que efectivamente, para o grupo de pequenas empresas producironse cambios significativos nas medias da RC4. No caso de empresas de tamaño medio, os cambios significativos producironse na RC3. Se consideramos o conxunto do sector, a hipótese nula de igualdade de medias pódese rexeitar só na RC4, o que se confirma coa análise Post Hoc Manovam (táboa M3 do anexo).

A redución de RC3 no grupo das medianas empresas ocorre por mor dunha diminución do peso dos acredores comerciais en relación coa CNN. A mellor xestión do endebedamento a curto prazo permitiu que este tamaño empresarial obteña unha maior sincronización entre a corrente de cobros e pagos ao longo do período. Cando se inicia a crise, o nivel de endebedamento a curto prazo, tanto de grandes como medianas empresas, era maior ao do conxunto do sector pero sobre todo, ao de pequenas empresas, a crise conseguiu que as medianas empresas melloren o seu nivel de débedas comerciais pero non o conseguiron para as grandes cadeas de comercialización.

A relación entre o Fondo de maniobra e a CNN expresada en $\mathrm{RC} 4$ indícanos para o grupo das pequenas empresa e o conxunto do sector unha melloría levada a cabo, principalmente, durante os primeiros anos da crise. Neste senso, é interesante observar que o grupo das grandes empresas mantiveron un Fondo de Maniobra negativo e sen cambios significativos durante o período. A súa maior capacidade de negociación permitiulles cobrar ao contado e seguir matendo prazos de pago cos seus provedores, beneficiándose así dunha financiación espontánea que, polo momento, parece vetada para empresas de menor tamaño.

\section{Análise do balance e a solvencia a longo prazo: As ratios de activo (RA)}

A táboa 11 amosa o resumo dos estatísticos descritivos das variables empregadas para analizar a estrutura do activo a través das ratios de activo (RA).

Táboa 11 Estatísticos descritivos RA e análise da varianza: 2008, 2010, 2012

\begin{tabular}{|l|l|l|l|l|l|l|l|l|l|l|l|l|l|}
\hline & \multicolumn{3}{|c|}{$\begin{array}{c}\text { Pequenas } \\
\text { N: 1011 }\end{array}$} & \multicolumn{3}{c}{$\begin{array}{c}\text { Medianas } \\
\text { N.47 }\end{array}$} & \multicolumn{3}{c}{$\begin{array}{c}\text { Grandes } \\
\text { N: 45 }\end{array}$} & \multicolumn{3}{c|}{ Total } \\
N: 1103 \\
\hline 2008 & Mediana & Media & DT & Mediana & Media & DT & Mediana & Media & DT & Mediana & Media & DT \\
\hline RA1 & 0,679 & 0,644 & 0,24 & 0,678 & 0,596 & 0,26 & 0,447 & 0,448 & 0,20 & 0,668 & 0,634 & 0,24 \\
\hline RA2 & 0,198 & 0,261 & 0,21 & 0,153 & 0,214 & 0,14 & 0,170 & 0,186 & 0,12 & 0,194 & 0,256 & 0,21 \\
\hline 2010 & Mediana & Media & DT & Mediana & Media & DT & Mediana & Media & DT & Mediana & Media & DT \\
\hline RA1 & 0,666 & 0,636 & 0,24 & 0,691 & 0,604 & 0,26 & 0,416 & 0,419 & 0,18 & 0,646 & 0,626 & 0,24 \\
\hline RA2 & 0,207 & 0,272 & 0,22 & 0,161 & 0,207 & 0,15 & 0,138 & 0,168 & 0,10 & 0,201 & 0,265 & 0,21 \\
\hline 2012 & Mediana & Media & DT & Mediana & Media & DT & Mediana & Media & DT & Mediana & Media & DT \\
\hline RA1 & 0,664 & 0,633 & 0,25 & 0,535 & 0,544 & 0,24 & 0,372 & 0,411 & 0,19 & 0,646 & 0,620 & 0,25 \\
\hline RA2 & 0,224 & 0,286 & 0,22 & 0,180 & 0,199 & 0,13 & 0,144 & 0,158 & 0,09 & 0,216 & 0,277 & 0,22 \\
\hline
\end{tabular}

Fonte: Elaboración propia. DT = Desviación títica 
Perante os descritivos sobre as ratios da estrutura de activo (RA), podemos intuír que só se produciron cambios significativos nas medias da ratio RA2. A priori poderíamos dicir que se produciu un incremento nas existencias que podería ser consecuencia dun estancamento nas vendas. Para comprobar se a media de cada RA difire ou non, de maneira significativa como consecuencia da crise, realizamos unha análise univariante da varianza Anova cun nivel de significación de 0,05 e cuxos resultados se amosa na táboa A4 do anexo. Atendendo ao estatístico $\mathrm{F}$ e ao p-valor xurdido da análise Anova rexeitamos a hipótese nula de igualdade de medias para a RA2 tanto para as empresas pequenas como para o conxunto total, o que se confirma coa análise Post Hoc Manova (Táboa M4 do anexo). A relación descrita en RA2 amosa o peso das existencias sobre o total dos activos e, para o caso das pequenas empresas, increméntase un 7,6\% de 2008 a 2012. Durante os anos da crise, as existencias das pequenas empresas creceron un $16,8 \%$ fronte ao $0,51 \%$ da cifra neta de negocio, daí que o incremento da RA2 reflictiría unha política inadecuada na xestión dos stocks de existencia que provocan unha caída de rendibilidade do conxunto das empresas, así como unha ineficiencia e ociosidade en parte dos recursos. Pola contra, tanto as medianas e grandes empresas amosan unha mellor xestión do stock de mercadorías. A posibilidade de estar departamentalizado e manter a persoal cualificado para cada departamento pode estar na base desta mellor xestión comercial.

\section{Ratios de Pasivo e Solvencia Xeral (RP)}

A táboa 12 amosa o resumo dos estatísticos descritivos das variables empregadas para analizar a estrutura do pasivo a través das ratios de pasivo (RP)

Táboa 12 Estatísticos descritivos RP e análise da varianza: 2008, 2010, 2012

\begin{tabular}{|c|c|c|c|c|c|c|c|c|c|c|c|c|}
\hline & \multicolumn{3}{|c|}{$\begin{array}{l}\text { Pequenas } \\
\text { N: } 1011\end{array}$} & \multicolumn{3}{|c|}{$\begin{array}{c}\text { Medianas } \\
\text { N: } 47\end{array}$} & \multicolumn{3}{|c|}{$\begin{array}{c}\text { Grandes } \\
\text { N: } 45\end{array}$} & \multicolumn{3}{|c|}{$\begin{array}{c}\text { Total } \\
\text { N:1103 }\end{array}$} \\
\hline 2008 & Mediana & Media & DT & Mediana & Media & DT & Mediana & Media & DT & Mediana & Media & DT \\
\hline RP1 & 0,404 & 1,030 & 2,26 & 0,549 & 1,366 & 1,90 & 0,491 & 0,619 & 0,71 & 0,409 & 1,028 & 2,20 \\
\hline RP2 & 0,145 & 0,231 & 0,24 & 0,078 & 0,131 & 0,15 & 0,101 & 0,169 & 0,16 & 0,135 & 0,224 & 0,24 \\
\hline RP3 & 0,853 & 0,768 & 0,24 & 0,921 & 0,869 & 0,15 & 0,899 & 0,830 & 0,16 & 0,864 & 0,775 & 0,24 \\
\hline RP4 & 0,019 & 0,027 & 0,06 & 0,016 & 0,021 & 0,02 & 0,013 & 0,020 & 0,01 & 0,019 & 0,027 & 0,06 \\
\hline RSG & 1,404 & 2,030 & 2,26 & 1,549 & 2,366 & 1,90 & 1,491 & 1,619 & 0,71 & 1,409 & 2,028 & 2,20 \\
\hline 2010 & Mediana & Media & DT & Mediana & Media & DT & Mediana & Media & DT & Mediana & Media & DT \\
\hline RP1 & 0,490 & 1,484 & 4,85 & 0,726 & 1,270 & 1,52 & 0,449 & 0,871 & 1,40 & 0,491 & 1,450 & 4,66 \\
\hline RP2 & 0,159 & 0,240 & 0,25 & 0,133 & 0,187 & 0,17 & 0,119 & 0,189 & 0,17 & 0,154 & 0,235 & 0,24 \\
\hline RP3 & 0,840 & 0,759 & 0,25 & 0,866 & 0,812 & 0,17 & 0,881 & 0,810 & 0,17 & 0,845 & 0,764 & 0,24 \\
\hline RP4 & 0,012 & 0,020 & 0,05 & 0,010 & 0,013 & 0,01 & 0,008 & 0,015 & 0,02 & 0,012 & 0,019 & 0,05 \\
\hline RSG & 1,490 & 2,484 & 4,85 & 1,726 & 2,270 & 1,52 & 1,449 & 1,871 & 1,40 & 1,491 & 2,450 & 4,66 \\
\hline 2012 & Mediana & Media & DT & Mediana & Media & DT & Mediana & Media & DT & Mediana & Media & DT \\
\hline RP1 & 0,536 & 1,794 & 7,20 & 0,804 & 1,197 & 1,24 & 0,457 & 0,893 & 1,46 & 0,537 & 1,730 & 6,90 \\
\hline RP2 & 0,142 & 0,230 & 0,24 & 0,129 & 0,194 & 0,19 & 0,128 & 0,174 & 0,16 & 0,142 & 0,226 & 0,24 \\
\hline RP3 & 0,857 & 0,769 & 0,24 & 0,870 & 0,805 & 0,19 & 0,871 & 0,825 & 0,16 & 0,857 & 0,773 & 0,24 \\
\hline RP4 & 0,015 & 0,032 & 0,32 & 0,014 & 0,018 & 0,01 & 0,010 & 0,017 & 0,02 & 0,015 & 0,031 & 0,30 \\
\hline RSG & 1,536 & 2,794 & 7,20 & 1,804 & 2,197 & 1,24 & 1,457 & 1,893 & 1,46 & 1,537 & 2,730 & 6,90 \\
\hline
\end{tabular}

Fonte: Elaboración propia. DT = desviación típica. 
Perante os descritivos sobre as ratios da estrutura de pasivo (RP), podemos intuír que só se produciron cambios significativos nas medias da ratio RP1 para pequenas empresas e para o total. O seu crecemento pódenos indicar que mellorou a súa autonomía financeira por aumento de fondos propios.

Ademais, intúense cambios significativos nas medias da ratio Ratio de Solvencia Xeral (RSG). $\mathrm{O}$ seu crecemento tanto nas pequenas empresas como no total pódenos indicar que, como consecuencia da crise, estas empresas melloraron as posibilidades de facer fronte ao total das súas débedas. Para comprobar se a media de cada RP e da RSX difire ou non, de maneira significativa como consecuencia da crise, realizamos unha análise univariante da varianza: Anova cun nivel de significación de 0,05 e cuxos resultados se amosan na táboa A5 do anexo e rexeitamos a hipótese nula de igualdade de medias para a RP1 e a RSX tanto para as empresas pequenas como para o total, o que se confirma coa análise Post Hoc Manova (Táboa M5 do anexo).

A RP1 mide a autonomía financeira das empresas. A dificultade de acceso ao crédito permitiu que o grupo de pequenas empresas aumente a súa autonomía financeira. A maior capitalización do seu valor patrimonial fortaleceu a súa autofinanciación situando a súa ratio de autofinanciación, en 2012, por enriba do dobre do das grandes empresas. A posición de forza das grandes empresas comerciais fronte aos seus prestamistas permitiulles manter os mesmos niveis de débeda e autofinanciación, antes que despois da crise, porén, as pequenas empresas non tiveron máis remedio que reestruturar as súas fontes de financiación, reducindo a allea e incrementando os recursos propios.

A RSX amosa a garantía que as empresas ofrecen aos seus acredores no hipotético caso de liquidación, no noso caso, obsérvase nas pequenas empresas e en conxunto que a solvencia mellorou ao longo da crise. Durante este período e malia a crise, as pequenas empresas do sector melloraron a súa solvencia por unha combinación de menor débeda e incremento do activo con fondos propios adicionais e posicionáronse, neste senso, por diante das medianas e grandes empresas.

\section{CONCLUSIÓNS}

O obxectivo deste traballo era ver como o sector de CNAE 2009-Rev2 471: Comercio ao por menor e distribución en establecementos non especializados resistiron á crise. Do traballo realizado despréndese que só algunhas ratios amosaron cambios significativos ao longo da crise, ademais, estes cambios, en xeral, obsérvanse unicamente para o grupo de pequenas empresas e, polo seu elevado peso sobre o conxunto da mostra, extrapólanse ao total do sector. Por tanto, en termos xerais, podemos dicir que a crise produciu efectos o suficientemente importantes como para dicir que o sector tivo que reorganizarse dende o punto de vista económico-financeiro pero estes cambios non afectaron a todos os tamaños empresariais: as grandes empresas, cun forte poder nos mercados, apenas sofreu a crise.

Da análise das ratios podemos ver que:

1. Tanto as pequenas empresas como o conxunto total viron como empeoraba a súa produtividade laboral (RO1), a súa marxe de explotación (RO2) e a súa rendibilidade sobre activos (RO5). Os aumentos de gastos de persoal, de custos fixos para a explotación e de gastos financeiros, entre outros, provocaron caídas na operatividade e rendibilidade empresarial. Ademais, a Rotación de Activos RO3 sofre un empeoramento entre 2008 e 2010, o que indica que, en xeral, o sector dispoñía de activos que non estaban sendo utilizados. Porén, despois de 2010 prodúcese unha melloría, o que podería ser sintomático dunha reactivación do negocio. Por iso, podemos dicir que a crise provocou unha menor eficiencia e rendibilidade no conxunto do sector pero só como efecto rebote ou contaxio do sufrido polo grupo de pequenas empresas. As medianas e grandes cadeas distribuidoras apenas viron cambiar as súas ratios de rendibilidade ou eficiencia. 
2. As pequenas, medianas e total de empresas vén diminuír o seu RF1 ou Cobertura de gastos financeiros, como consecuencia dun desapancamento tanto á curto como á longo plazo, o que permitiu que os valores do RF1 se igualen ao das grandes empresas, que partían dunha mellor cobertura financeira, non por un menor nivel de endebedamento senón por unha maior capacidade para negociar os seus gastos.

3. Tanto nas pequenas empresas como no total, aumentou significativamente a RC4 o que significa que mellorou o fondo de maniobra empresarial. A partir de 2010, estas empresas teñen unha maior liquidez e poden facer fronte mellor aos seus inmediatos a pesar de ser un sector que, tradicionalmente, se caracteriza por ter un fondo de maniobra negativo. $\mathrm{O}$ feito de cobrar ao contado e poder pagar a prazos aos acredores comerciais lles permite beneficiarse dunha financiación espontánea, nembargantes, a crise provocou que este beneficio só o manteñan as grandes empresas do sector. A súa maior capacidade de negociación e a súa posición de forza permitiulles manter, durante toda a crise, un fondo de maniobra negativo.

Por outra banda e só para o caso das empresas de tamaño medio, mellorou a RC3 que mide o volume de acredores coa cifra de vendas. A crise obrigoulles a facer máis compras ao contado e menos a crédito. Porén, esta reestruturación do volume de acredores non lles fai posicionarse ao mesmo nivel que o conxunto nin que as pequenas empresas, que teñen menos acredores.

4. Producíronse significativos aumentos no RA2 tanto para pequenas como para o conxunto das empresas. O crecemento das existencias por enrima do aumento do total de activos avala a tese de que este grupo de empresas xestionou peor os stocks de mercadorías que as súas homólogas en tamaños superiores, o que pode que lles levara a peores resultados e eficiencia.

5. As medianas e grandes empresas, ao iniciarse a crise, mantiñan peores niveis de autofinanciación pero ademais, non tiveron a necesidade de modificar a súa estrutura financeira. Daí que só se produciron cambios significativos no nivel de autofinanciación para o grupo de pequenas empresas e do total da mostra: ratio RP1. A maior capitalización do seu valor patrimonial fortaleceu a financiación propia en sintonía coa media do sector e dalle un nivel de autofinanciación do dobre do das grandes empresas.

A Solvencia Xeral RSX mellora nas pequenas empresas e no total da mostra. A pesar da crise, a combinación dunha menor débeda xunto a un incremento do activo con fondos propios adicionais favoreceron a recuperación.

En resumo, vimos que as empresas do sector manteñen un comportamento anticíclico en relación ás variables macroeconómicas como o PIB p.m., ou o consumo interno medido como Gasto Medio por Fogar. Namentres as variables macroeconómicas caen, a cifra neta de negocio do grupo de análise crece un $8,4 \%$, sobre todo, a partir de 2010. Posiblemente este comportamento débese ao peso dos produtos que comercializa o sector que se poden considerar bens de primeira necesidade. O devandito comportamento avalaría a tese da teoría de consumo na relación renda e consumo para os bens de primeira necesidade e por tanto, permitiríanos aceptar a H.1 na medida que o sector tivo que se reorganizar como consecuencia da crise e perdeu eficiencia e rendibilidade, pero a especialización en comercialización de bens de primeira necesidade cunha elasticidade demanda-renda baixa permitiulles seguir mantendo niveis aceptables, sobre todo, para os tamaños empresariais máis grandes.

Por outra banda, comprobamos que foi significativo o esforzo de capitalización malia que só no caso das empresas de tamaño máis pequeno. Os aumentos de recursos propios orientados a diminuír a dependencia na financiación allea, así como a diminución dos pasivos a curto prazo no grupo de medianas fixeron que mellorara o nivel de autofinanciación do sector. Por mor destes resultados, podemos dicir que a crise financeira iniciada a principios de 2008 obrigou a reestruturar o nivel de endebedamento no conxunto sectorial, o que nos permite admitir a H2.1 na que se expoñía que a crise 
financeira dificultaría o acceso ao crédito orixinando neste sector un efecto de desapancamento pero tamén aceptaríamos a H2.2, xa que só as empresas de tamaño pequeno estiveron afectadas por unha reestruturación financeira. A substitución da fonte de financiación allea pola propia permitiulles duplicar a súa ratio de autonomía financeira moi por enriba da das medianas e grandes empresas do grupo. O gran tamaño dalgunhas destas empresas permítelles ter unha maior capacidade de negociación, tanto con entidades de crédito como con acredores, e non necesitaron recompoñer a súa financiación.

Por todo isto, podemos dicir que, a pesar de que o sector do comercio ao por menor goza dunha escasa elasticidade demanda-renda que lle permita manter un comportamento anticíclico, os esforzos para sobrevivir á actual crise foron inversamente proporcionais ao tamaño empresarial. As empresas máis pequenas son as que sofreron maiores perdas de rendibilidade e necesitaron unha maior reorganización da súa estrutura financeira.

\section{Bibliografía}

Azofra, V. Y Rodríguez, J. A. (2012). El Endeudamiento De La Empresa Española: Teorías Y Realidades. Papeles De Economía Española, 132, Pp. 37-61

Boletín Económico Del Ice, (2011). Núm. 3015

Booth, L.; Aivazian, V. A.; Demirguc-Kunt, A. Y Maksimovic, V. (2001). Capital Structures In Developing Countries. Journal Of Finance, 56(1), Pp. 87-130.

Demirgüc-Kunt, A. Y Maksimovic, V. (1999). Institutions, Financial Markets And Firm Debt Maturity. Journal Of Financial Economics, 54, Pp. 295-336.

Directiva 2013/34/ Ue Del Parlamento Europeo Y Del Consejo De 26 De Junio De 2013

Fernández, F. (2010). Crisis Financiera, Crisis Real Y Competitividad De La Economía Española. Cuadernos De Pensamiento Político, 37, Pp. 37-60.

Galbraith, J. K. (1991). Breve Historia De La Euforia Financiera. Barcelona: Ariel.

García, J. A. Y Delgado, J. (2012). Análisis De La Competencia En El Mercado Minorista De Distribución En España. The Brattle Group, Ltd. Sucursal En España. Madrid.

González, V. Y González, F. (2008). Influence Of Bank Concentration And Institutions On Capital Structure: New International Evidence. Journal Of Corporate Finance, 14, Pp. 363-375.

González, C. Y Jareño, F. (2014). Financial Analysis Of The Main Hotel Chains Of The Spanish Tourism Sector. Regional And Sectoral Economic Studies, Vol. 14-2, Pp. 91-108

Hanousek, J. Y Shamshur, A. (2011). A Stubborn Persistence: Is The Stability Of Leverage Ratios Determined By The Stability Of The Economy? Journal Of Corporate Finance, 17(5): 1360-1376.

Jordà, O.; Schularik, M. Y Taylor, A. M. (2011). When Credit Bites Back: Leve-Rage, Business Cycles And Crises. Nber Working Paper, 17261.

Keynes, J.F. 1943 (Reimpreso En 1997). Teoría General De La Ocupación, El Interés Y El Dinero. Fondo De Cultura Económica/ Serie Economía. Mexico

Kugman, P. (2009). "How Did Economists Get It So Wrong?" New York Times Magazine, 2 De Septiembre.

Miguel, A. De, Y Pindado, J. (2001). Determinants Of Capital Structure: New Evidence From Spanish Panel Data. Journal Of Corporate Finance, 7, Pp. 77-79.

Minsky, H. (1982). The Financial Instability Hypothesis. The Levy Economics Institute, Working Paper, 74 .

Ortega, E. Y Peñasola, J. (2012). Claves De La Crisis Económica Española Y Retos Para Crecer En La Uem. Banco De España. Documentos Ocasionales, Núm. 1201.

Rubio, G. Y Sogorb, F. (2011). The Adjustment To Target Leverage Of Spanish Public Firms: Macroeconomic Conditions And Distance From Target. Revista De Economía Aplicada, 57, Pp. 35-63. Rajan, R. Y Zingales, L. (1995). What Do We Know About Capital Structure? Some Evidence From International Data. The Journal Of Finance, 50(5), Pp. 1421-1460.

Schularik, M. Y Taylor, A. (2012). Credit Booms Gone Bust: Monetary Policy, Leverage Cycles And Financial Crises, 1870-2008. American Economic Review,

Stiglitz, J.E. (2010). Caída Libre. El Libre Mercado Y El Hundimiento De La Economía Mundial. Taurus. Madrid. 


\section{Anexo on line}

\section{A1. DEFINICIÓN DE RATIOS UTILIZADOS}

I. Para el análisis de la cuenta de Pérdidas y Ganancias: Ratios operativos o de rentabilidades y Ratios Financieros

\section{Ratios operativos o de rentabilidades (RO)}

Para analizar el resultado de la actividad económica de nuestras empresas objeto de estudio, hemos confeccionado un grupo de ratios, denominados Ratios Operativos: RO (tabla 3) en los que se analiza la evolución de los resultados de las empresas medidos a través de la Cifra Neta de Negocio (CNN), del Resultados de Explotación (REX) el Resultado Antes de Impuestos (RAI) o el Resultado del Ejercicio (REJ) y puestos en comparación con los Gastos de Personal (GP), con el Total Activo (TA) o con Patrimonio Neto (PN). De su estudio, se observa la evolución de la actividad empresarial, su rentabilidad y su operatividad, lo que nos permitirá comprobar si, como consecuencia de la crisis, nuestras empresas han mejorado o no su eficiencia.

Tabla 3: Ratios Operativos (RO)

\begin{tabular}{lll}
\hline Ratio & definición & Fórmula \\
\hline R01 & Gastos de personal / Cifra neta de negocios & GP/CNN \\
R02 & Resultado explotación/ Cifra neta de negocios & REX/ CNN \\
R03 & Cifra neta de negocios / Total activo & CNN/TA \\
R04 & Resultado antes de impuestos / Patrimonio neto & RAI/ PN \\
R05 & Resultado antes de impuestos/ Total activo & RAI/TA \\
R06 & Resultado después de impuestos / Patrimonio neto & REJ/ PN \\
\hline
\end{tabular}

\section{Ratios Financieros (RF)}

Los ratios financieros (Tabla 4) nos dan una imagen del coste de las deudas empresariales y se obtienen mediante la comparación de los Gastos Financieros (GF), Resultado Financiero (RF) con la CNN o el REX. Con ellos, se puede ver el efecto sobre las empresas de haber realizado cambios o no en la forma de financiación.

Tabla 4: Ratios Gastos e Ingresos Financieros (RF)

\begin{tabular}{llc}
\hline Ratio & definición & Fórmula \\
\hline RF1 & Gastos financieros/ Cifra neta de negocios & GF/ CNN \\
RF2 & Gastos financieros/ Resultado explotación & GF/ REX \\
RF3 & Resultado financiero / Cifra neta de negocios & $\mathrm{RF} / \mathrm{CNN}$ \\
RF4 & Resultado financiero / Resultado explotación & $\mathrm{RF} / \mathrm{REX}$ \\
\hline
\end{tabular}

\section{I.Para el análisis de la liquidez: Ratios Corrientes (RC)}

Con este grupo de ratios se analizar la evolución del capital corriente. Comparamos masas patrimoniales tanto de activo como pasivo corrientes, tales como Existencia (EX), Deudores Comerciales (D) Acreedores Comerciales (ACR), Activo Corriente (AC) con la Cifra Neta de Negocio (CNN) y con el Pasivo Corriente (PC). La comparación de las diferentes cuentas nos indicará el peso de la financiación ajena, el fondo de maniobra y la capacidad de hacer frente a las deudas a corto plazo. Los Ratios Corrientes son los de la tabla 5.

Tabla 5: Ratios Corrientes (RC) 


\begin{tabular}{lll}
\hline Ratio & definición & Fórmula \\
\hline RC1 & Existencias / Cifra neta de negocios & EX/ CNN \\
RC2 & Deudores comerciales / Cifra neta de negocios & D/ CNN \\
RC3 & Acreedores comerciales / Cifra neta de negocios & ACR/ CNN \\
RC4 & Capital circulante / Cifra neta de negocios & (AC-PC)/ CNN \\
RC5 & Activo corriente/ Pasivo corriente & AC/ PC \\
RC6 & (Activo circulante-Existencias) / Pasivo corriente & (AC-EX)/ PC \\
RC7 & Tesorería/ pasivo corriente & TES/ PC \\
\hline
\end{tabular}

\section{I.Para el análisis del balance y la solvencia a largo plazo: Ratios de Activo, Ratios de} Pasivo y Ratio de Solvencia General

Los ratios de solvencia a largo plazo pretenden determinar la capacidad de las empresas para afrontar sus deudas. De su análisis se puede conocer la capacidad de las empresas para hacer frente a todas sus deudas, la evolución de la deuda con las inversiones o el nivel de endeudamiento empresarial.

\section{Ratios de Activo (RA)}

Los Ratios de Activo nos ofrecen un análisis vertical de las diferentes partidas del activo como son el Activo Circulante (AC) o las Existencias (EX) con lo que se puede conocer el peso de cada masa patrimonial sobre el conjunto del Activo (TA) y su evolución durante la crisis. Los ratios de activo son descritos en la tabla 6.

Tabla 6: Ratios Estructura del Activo (RA)

\begin{tabular}{lll}
\hline Ratio & definición & Fórmula \\
\hline RA1 & Activo circulante / Total activo & $\mathrm{AC} / \mathrm{TA}$ \\
RA2 & Existencias/ Total activo & $\mathrm{EX/TA}$ \\
\hline
\end{tabular}

\section{Ratios de Pasivo y Solvencia General (RP)}

Los ratios de pasivo nos ofrecen la evolución de la estructura financiera de las empresas. La crisis ha endurecido las condiciones de acceso a los mercados financieros y es conveniente estudiar los cambios en las distintas formas de financiación mediante la evolución del Patrimonio Neto (PN), Pasivo no Corriente (PNC), Pasivo Corriente (PC), incluso el coste de financiar la deuda Gastos Financieros (GF) respecto al Total de financiación ajena o Total Pasivo (TP). Los ratios de pasivo son los de la tabla 7

Tabla 7: Ratios de la Estructura de la Pasivo (RP)

\begin{tabular}{lll}
\hline Ratio & definición & Fórmula \\
\hline RP1 & Patrimonio Neto/ Total Pasivo & PN/TP \\
RP2 & Pasivo no corriente / Total pasivo & PNC/ TP \\
RP3 & Pasivo corriente / Total pasivo & PC/ TP \\
RP4 & Gastos Financieros/ Total pasivo & GF/ TP \\
RSG & Total activo / total pasivo & TA/TP \\
\hline
\end{tabular}

\section{A2. distribución al por menor e hipótesis planteadas}

La distribución al por menor y la demanda de bienes de consumo

Si bien, son abundantes y los estudios que relacionan crisis financiera y grado de endeudamiento empresarial, no lo son tanto aquellos que hace lo propio respecto al sector y menos sobre el sector del comercio y la distribución al por menor.

En este sentido, sabemos que la función de demanda de consumo depende de la renta disponible, adoptando una ecuación como la expresada en (1) 
$\mathrm{C}_{0}$ sería el consumo autónomo que no depende de la renta, $\left(\mathrm{C}_{0}>0\right)$

$\mathrm{C}_{1}$ es la propensión marginal a consumir. Mide el efecto de una unidad monetaria adicional de renta disponible sobre el consumo $\left(0<\mathrm{C}_{1}<1\right)$

$\mathrm{Y}_{\mathrm{d}}$ es la renta disponible una vez pagados los impuestos. Variaciones en el nivel de renta disponible, afectan en el mismo sentido al consumo, lo que se conoce como elasticidad demanda renta positiva.

$$
\mathrm{sy}_{d}=\frac{\text { variación porcentual cantidad demandada }}{\text { variación porcentual renta }}>\mathbf{0}
$$

Sin embargo, para el caso de los bienes de primera necesidad, que son principalmente los ofrecidos por el sector del comercio y distribución al por menor (Boletín Económico del ICE, 2011 ), esta elasticidad es próxima a cero ( $\boldsymbol{s y _ { d } \approx 0}$ ).

La baja elasticidad demanda renta y el elevado nivel de concentración del mercado en manos de cinco grandes cadenas podrían estar en la base de que el sector, principalmente el grupo de grandes empresas, ha sufrido con menor intensidad la crisis, por tanto, en este trabajo se amplían las visiones de los efectos de la crisis en la economía al centrarlo en un sector concreto como es el del comercio y la distribución en España.

Formulación de hipótesis

A pesar de la fuerte contracción en el consumo nacional, las ventas de las empresas del sector CNAE 2009-Rev2 471: "Comercio al por menor en establecimientos no especializados" no se vio tan mermada como la caída del PIB o del Gasto Medio por Hogar y, a partir de 2010, empezó a recuperar parte de las posiciones pérdidas (Tabla 1). La especialización en la venta de productos de muy poca elasticidad demanda-renta y la concentración del mercado en manos de unos pocos distribuidores ${ }^{1}$, pueden estar en la base de este comportamiento. De ahí que formulemos nuestra primera hipótesis

H1: El sector de la distribución y comercialización al por menor CNAE 471 ha sufrido con menor intensidad los efectos de la crisis.

La caída del PIB y la fuerte reducción de la demanda interna han provocado pocos cambios en las cuentas empresariales. La especialización en venta de productos con una elasticidad demanda-renta baja y el alto grado de concentración del mercado han permitido que, en términos generales pero sobre todo, para el caso de las grandes empresas distribuidoras, la crisis les haya dado brío y situado en mejor posición para afrontar los nuevos retos.

Las empresas comerciales y de distribución al por menor han tenido que recomponer sus pasivos en menor proporción que las empresas de otros sectores (Tabla 2). La contracción del crédito y su encarecimiento, a pesar de la caída de los tipos de interés oficiales, provocó que las empresas que antes habían tenido un fuerte nivel de endeudamiento intentaran desapalancarse. Las bajas tasas de beneficio empresarial dificultaban la devolución de los créditos y evidenciaban el sobredimensionamiento del endeudamiento, lo que iba a llevar ineludiblemente, a una restructuración de los pasivos contables en las empresas. La estructura financiera empresarial debía cambiar, incluso en un sector poco afectado por la crisis, lo que nos lleva a formular nuestra segunda hipótesis.

1Entre 2008 y 2011 el grado de concentración del mercado creció, sobre todo en comunidades autónomas como El País Vasco, Comunidad Valenciana, Madrid o Andalucía y 3 grandes cadenas distribuidoras controlaban el 68\% de la cuota total del mercado. (García, J.A. y Delgado, J 2012). 
H2.1: A pesar de que las empresas del sector de la distribución al por menor han sufrido menos la crisis, la dificultad para acceder al crédito y su encarecimiento ha originado un efecto de desapalancamiento y de recapitalización de los fondos propios.

No obstante, la existencia de grandes cadenas de distribución y comercialización que controlan el mercado y actúan como oligopolios con los fabricantes-proveedores, va a provocar que la reestructuración financiera del sector sea pequeña, lo que no lleva a formular otra sub-hipótesis.

Las empresas H2.2: No todas las empresas del sector van a estar afectadas por la reestructuración financiera. más grandes, con mayor capacidad de negociación con entidades de crédito y sobre todo, con acreedores, apenas tendrán necesidad de recomponer su deuda mientras que las más pequeñas buscarán sustituir deuda ajena por autofinanciación.

Tabla A1. Contrastes de hipótesis y análisis de varianza Anova de un factor de los ratios (RO)

\begin{tabular}{|c|c|c|c|c|c|c|c|c|}
\hline & \multicolumn{2}{|c|}{ Pequeñas } & \multicolumn{2}{c|}{ Medianas } & \multicolumn{2}{c|}{ Grandes } & \multicolumn{2}{c|}{ Total } \\
\hline & F & Sig. & F & Sig. & F & Sig. & F & Sig. \\
\hline R01 & 4,19 & 0,015 & 0,71 & 0,491 & 0,68 & 0,508 & 4,48 & 0,011 \\
\hline R02 & 12,78 & 0,000 & 0,26 & 0,764 & 0,88 & 0,415 & 13,51 & 0,000 \\
\hline R03 & 2,73 & 0,065 & 0,32 & 0,725 & 0,38 & 0,679 & 3,04 & 0,048 \\
\hline R05 & 16,98 & 0,000 & 0,44 & 0,644 & 1,39 & 0,251 & 18,22 & 0,000 \\
\hline
\end{tabular}

Tabla M1 Contraste de hipótesis Multivariante Manova (RO)

\begin{tabular}{|l|c|c|c|c|c|}
\hline HSD TUCKEY & \multicolumn{5}{|l|}{ Significación al 95\% . } \\
\hline RO & Grupos de Comparación & Pequeñas & Medianas & Grandes & Total \\
\hline \multirow{2}{*}{ R01 } & $2008-10$ & 0,090 & 0,894 & 0,973 & 0,117 \\
& $2008-12$ & 0,016 & 0,736 & 0,510 & 0,010 \\
& $2010-12$ & 0,788 & 0,466 & 0,655 & 0,616 \\
\hline \multirow{2}{*}{ R02 } & $2008-10$ & 0,796 & 0,827 & 0,943 & 0,819 \\
& $2008-12$ & 0,000 & 0,995 & 0,405 & 0,000 \\
& $2010-12$ & 0,000 & 0,776 & 0,609 & 0,000 \\
\hline \multirow{2}{*}{ R03 } & $2008-10$ & 0,057 & 0,960 & 0,653 & 0,044 \\
& $2008-12$ & 0,289 & 0,709 & 0,895 & 0,219 \\
& $2010-12$ & 0,726 & 0,868 & 0,906 & 0,757 \\
\hline \multirow{2}{*}{ R05 } & $2008-10$ & 0,173 & 0,967 & 0,926 & 0,202 \\
& $2008-12$ & 0,000 & 0,782 & 0,247 & 0,000 \\
& $2010-12$ & 0,000 & 0,639 & 0,443 & 0,000 \\
\hline
\end{tabular}


Tabla A2 Contrastes de hipótesis y análisis de varianza Anova de un factor de los ratios (RF)

\begin{tabular}{|c|c|c|c|c|c|c|c|c|}
\hline & \multicolumn{2}{|c|}{ Pequeñas } & \multicolumn{2}{c|}{ Medianas } & \multicolumn{2}{c|}{ Grandes } & \multicolumn{2}{c|}{ Total } \\
\hline & F & Sig. & F & Sig. & F & Sig. & F & Sig. \\
\hline RF1 & 11,37 & 0,000 & 3,28 & 0,041 & 0,01 & 0,986 & 12,28 & 0,000 \\
\hline RF4 & 1,10 & 0,331 & 0,27 & 0,758 & 0,61 & 0,544 & 1,10 & 0.332 \\
\hline
\end{tabular}

Tabla M2 Contraste de hipótesis Multivariante Manova (RF)

\begin{tabular}{|c|c|c|c|c|c|}
\hline HSD TUCKEY & \multicolumn{5}{l|}{ Significación al 95\% } \\
\hline RF & Grupos de Comparación & Pequeñas & Medianas & Grandes & Total \\
\hline \multirow{3}{*}{ RF1 } & $2008-10$ & 0,000 & 0,036 & 0,986 & 0,000 \\
& $2008-12$ & 0,001 & 0,209 & 0,991 & 0,001 \\
& $2010-12$ & 0,717 & 0,692 & 0,999 & 0,678 \\
\hline \multirow{2}{*}{ RF4 } & $2008-10$ & 0,428 & 0,842 & 0,729 & 0,436 \\
& $2008-12$ & 0,992 & 0,762 & 0,533 & 0,989 \\
& $2010-12$ & 0,377 & 0,990 & 0,947 & 0,373 \\
\hline
\end{tabular}

Tabla A3: Contrastes de hipótesis y análisis de varianza Anova de un factor de los ratios (RC)

\begin{tabular}{|l|c|c|c|c|c|c|c|c|}
\hline & \multicolumn{2}{|c|}{ Pequeñas } & \multicolumn{2}{c|}{ Medianas } & \multicolumn{2}{c|}{ Grandes } & \multicolumn{2}{c|}{ Total } \\
\hline & F & Sig. & F & Sig. & F & Sig. & F & Sig. \\
\hline RC2 & 1,69 & 0,184 & 0,64 & 0,529 & 0,00 & 0,997 & 1,98 & 0,138 \\
\hline RC3 & 0,30 & 0,736 & 3,10 & 0,048 & 0,25 & 0,776 & 0,47 & 0,621 \\
\hline RC4 & 5,33 & 0,005 & 0,54 & 0,582 & 0,10 & 0,905 & 5,34 & 0,005 \\
\hline RC5 & 0,98 & 0,375 & 0,08 & 0,916 & 0,26 & 0,768 & 0,97 & 0,376 \\
\hline RC6 & 0,98 & 0,375 & 0,09 & 0,913 & 0,46 & 0,632 & 0,97 & 0,376 \\
\hline RC7 & 0,98 & 0,373 & 0,27 & 0,760 & 0,15 & 0,860 & 0,99 & 0,371 \\
\hline
\end{tabular}

Tabla M3 Contraste de hipótesis Multivariante Manova (RC)

\begin{tabular}{|l|c|c|c|c|c|}
\hline HSD TUCKEY & Significación al 95\% . & \multicolumn{3}{l|}{ Total } \\
\hline RC & $\begin{array}{c}\text { Grupos de } \\
\text { Comparación }\end{array}$ & Pequeñas & Medianas & Grandes & \\
\hline \multirow{3}{*}{ RC2 } & $2008-10$ & 0,929 & 0,980 & 1,000 & 0,947 \\
& $2008-12$ & 0,184 & 0,655 & 0,998 & 0,146 \\
\hline \multirow{3}{*}{ RC3 } & $2010-12$ & 0,355 & 0,544 & 0,997 & 0,274 \\
\hline \multirow{3}{*}{ RC4 } & $2008-10$ & 0,791 & 0,661 & 0,987 & 0,886 \\
& $2008-12$ & 0,998 & 0,040 & 0,774 & 0,860 \\
\hline \multirow{3}{*}{ RC5 } & $2010-12$ & 0,761 & 0,268 & 0,859 & 0,593 \\
\hline \multirow{3}{*}{ RC6 } & $2008-10$ & 0,020 & 0,553 & 0,994 & 0,016 \\
& $2008-12$ & 0,010 & 0,896 & 0,941 & 0,011 \\
\hline \multirow{3}{*}{ RC7 } & $2010-12$ & 0,966 & 0,823 & 0,904 & 0,991 \\
& $2008-10$ & 0,479 & 0,961 & 0,795 & 0,480 \\
& $2008-12$ & 0,415 & 0,988 & 0,818 & 0,990 \\
& $2010-12$ & 0,457 & 0,910 & 0,999 & 0,416 \\
\hline
\end{tabular}


Tabla A4 Contrastes de hipótesis y análisis de varianza Anova de un factor de los ratios (RA)

\begin{tabular}{|c|c|c|c|c|c|c|c|c|}
\hline & \multicolumn{2}{|c|}{ Pequeñas } & \multicolumn{2}{c|}{ Medianas } & \multicolumn{2}{c|}{ Grandes } & \multicolumn{2}{c|}{ Total } \\
\hline & F & Sig. & F & Sig. & F & Sig. & F & Sig. \\
\hline RA1 & 0,51 & 0,599 & 0,72 & 0,487 & 0,46 & 0,632 & 0,87 & 0,417 \\
\hline RA2 & 2,93 & 0,054 & 0,11 & 0,891 & 0,76 & 0,469 & 2,32 & 0,098 \\
\hline
\end{tabular}

Tabla M4 Contraste de hipótesis Multivariante Manova (RA)

\begin{tabular}{|l|c|c|c|c|c|}
\hline HSD TUCKEY & Significación al 95\% . \\
\hline RA & $\begin{array}{c}\text { Grupos de } \\
\text { Comparación }\end{array}$ & pequeñas & Medianas & Grandes & Total \\
\hline \multirow{3}{*}{ RA1 } & $2008-10$ & 0,765 & 0,989 & 0,758 & 0,729 \\
& $2008-12$ & 0,590 & 0,595 & 0,635 & 0,387 \\
& $2010-12$ & 0,957 & 0,517 & 0,978 & 0,845 \\
\hline \multirow{2}{*}{ RA2 } & $2008-10$ & 0,542 & 0,971 & 0,709 & 0,630 \\
& $2008-12$ & 0,041 & 0,880 & 0,448 & 0,080 \\
\hline
\end{tabular}

Tabla A5 Contrastes de hipótesis y análisis de la varianza Anova de un factor de los ratios (RP)

\begin{tabular}{|l|c|c|c|c|c|c|c|c|}
\hline & \multicolumn{2}{|c|}{ Pequeñas } & \multicolumn{2}{c|}{ Medianas } & \multicolumn{2}{c|}{ Grandes } & \multicolumn{2}{c|}{ Total } \\
\hline & F & Sig. & F & Sig. & F & Sig. & F & Sig. \\
\hline RP1 & 5,47 & 0,004 & 0,13 & 0,876 & 0,67 & 0,513 & 5,48 & 0,004 \\
\hline RP2 & 0,42 & 0,654 & 1,82 & 0,165 & 0,17 & 0,841 & 0,61 & 0,539 \\
\hline RP3 & 0,42 & 0,654 & 1,82 & 0,165 & 0,17 & 0,841 & 0,61 & 0,539 \\
\hline RP4 & 0,96 & 0,3823 & 2,73 & 0,068 & 0,48 & 0,619 & 1,02 & 0,360 \\
\hline RSG & 5,47 & 0,004 & 0,13 & 0,876 & 0,67 & 0,513 & 5,48 & 0,004 \\
\hline
\end{tabular}

Tabla M5 Contraste de hipótesis Multivariante Manova (RP)

\begin{tabular}{|l|c|c|c|c|c|}
\hline HSD TUCKEY & Significación al 95\% . & \multicolumn{3}{l|}{ Total } \\
& $\begin{array}{c}\text { Grupos de } \\
\text { Comparación }\end{array}$ & Pequeñas & Medianas & Grandes & 0,117 \\
& $2008-10$ & 0,122 & 0,955 & 0,605 & 0,003 \\
RP1 & $2008-12$ & 0,003 & 0,865 & 0,557 & 0,402 \\
\hline \multirow{3}{*}{ RP2 } & $2010-12$ & 0,390 & 0,974 & 0,996 & 0,551 \\
& $2008-10$ & 0,731 & 0,273 & 0,839 & 0,986 \\
& $2008-12$ & 0,994 & 0,195 & 0,990 & 0,663 \\
\hline \multirow{3}{*}{ RP3 } & $2010-12$ & 0,680 & 0,984 & 0,906 & 0,551 \\
& $2008-10$ & 0,731 & 0,273 & 0,839 & 0,986 \\
RP4 & $2008-12$ & 0,994 & 0,195 & 0,990 & 0,663 \\
\hline \multirow{3}{*}{ RSG } & $2010-12$ & 0,680 & 0,984 & 0,906 & 0,604 \\
& $2008-10$ & 0,868 & 0,055 & 0,591 & 0,885 \\
& $2008-12$ & 0,359 & 0,619 & 0,859 & 0,341 \\
\hline
\end{tabular}

Revista Galega de Economía: http:/ / www.usc.es/ econo/ RGE/ benvidag.htm https:/ / ideas.repec.org.s/ sdo/ regaec.html 